\title{
İtki Dalgalarının Oluşumunda Ölçek Etkisi, Hareket Süresi ve Çarpma Hızının Model Deneyler ve 3 Boyutlu Nümerik Simülasyonlarla Değerlendirilmesi
}

\author{
Assessment of Scale Effect, Travel Time, Impact Velocity on Forming of Impulse Waves \\ using Model Tests, 3D Numerical Simulations
}

\author{
Murat KARAHAN*1,a, Hakan ERSOY ${ }^{1, b}$, Tuğçe ANILAN ${ }^{2, c}$ \\ ${ }^{1}$ Karadeniz Teknik Üniversitesi, Mühendislik Fakültesi, Jeoloji Mühendisliği Bölümü, 61080, Trabzon \\ ${ }^{2}$ Karadeniz Teknik Üniversitesi, Mühendislik Fakültesi, İnşaat Mühendisliği Bölümü, 61080, Trabzon
}

• Geliş tarihi / Received: 27.01.2020 • • Düzeltilerek geliş tarihi / Received in revised form: 17.03.2020 • Kabul tarihi / Accepted: 30.03 .2020

\begin{abstract}
$\ddot{O} \mathbf{z}$
İtki dalgaları, baraj veya göl alanlarında heyelan, kaya düşmesi, çığ, moloz ve çamur akması gibi doğal jeolojik olayların tetiklemesi sonucu meydana gelmektedir. Oluşan dalganın hızı ve yüksekliği yamaç boyunca eğim aşağı hareket eden kütlenin suya çarpma hızına bağlıdır. Çarpma hızı ise yamaç eğimine, hareket eden kütlenin konumuna, fiziksel ve mekanik özelliklerine bağlıdır. İtki dalgalarının özellikleri, sayısal ve ampirik yaklaşımlarla belirleneceği gibi hidrolik modellerle de belirlenebilmektedir. Bu çalışmada ise ölçek etkisi ve hareket eden kütlenin suya çarpma hızları farklı yöntemler kullanılarak modellenmiş ve elde edilen sonuçlar karşılaştırılmıştır. Çalışma kapsamında tasarlanan bir hidrolik model üzerinde fiziksel deneyler yapılmış, $0.4 \mathrm{~m}^{3}$ hacimli bir havuz, yükleme rampası, yüksek hızlı kamera ve akışkan olarak su kullanılmıştır. Farklı rampa açılarında hareket eden suyun havuz tabanına ulaşma süresi, çarpma hızı ve havuzda oluşan dalga yüksekliği değerleri hesaplanmıştır. Aynı model, 3 boyutlu nümerik çözümleme yapan FLOW-3D programı kullanılarak farklı ölçeklerde tanımlanmış (0.1x, 1x, 10x, 100x, 1000x), farklı yoğunlukta akışkanlar $\left(800-2000 \mathrm{~kg} / \mathrm{m}^{3}\right)$ kullanılarak çözümleme yapılmış ve serbest su seviyesi yükseklikleri tespit edilmiştir. Nümerik ve hidrolik model kullanılarak tanımlanan parametreler ampirik ilişkiler kullanılarak da belirlenmiştir. Yapılan nümerik çalışmalardan elde edilen sonuçlara göre hidrolik model hangi ölçekte olursa olsun elde edilen sonuçların ölçekten etkilenmediği tespit edilmiştir. Her 3 yöntem kullanılarak belirlenen, su hareket hızı, çarpma hızı ve maksimum dalga yüksekliği değerleri arasındaki farkın \%2-3 arasında değiştiği tespit edilmiştir. Elde edilen sonuçlar basit rezervuarlar için ve kısa mesafeler için ölçek etkisinin önemsiz olduğunu ve hesaplamalarda ampirik ilişkilerin yeterli olabileceğini göstermiştir.
\end{abstract}

Anahtar kelimeler: Ampirik Eşitlikler, Çarpma Hızı, Dalga Yüksekliği, Hidrolik Model, İtki Dalgası, Nümerik Model

\begin{abstract}
Impulse waves occur as a result of natural geological events such as landslides, rock falls, avalanches, rubble and mudflows in dam or lake areas. The celerity and height of the formed wave depends on the impact velocity of the mass moving into the water. The impact velocity depends on the slope, the location of the sliding materials, and their physical and mechanical properties. The characteristics of the impulse waves can be determined by numerical and empirical approaches as well as by hydraulic models. In this study, the scale effect and the slide impact velocity were modeled using different methods and the results obtained were compared. A hydraulic model, which was made of a pool of 0.4 $m 3$ volume, loading ramp, high speed camera, and water as fluid, was designed to carry out the physical experiments within the scope of the study. The time it takes for the fluid to reach the bottom of the pool, the impact velocity of the fluid and the wave height were calculated for various ramp angles. The same model has been defined in different scales $(0.1 x, 1 x, 10 x, 100 x, 1000 x)$ using FLOW-3D program that performs 3-dimensional numerical analysis. Analysis were carried out using different density fluids $\left(800-2000 \mathrm{~kg} / \mathrm{m}^{3}\right)$, and values of free surface elevation were determined. The parameters defined using the numerical and hydraulic model were also determined using empirical relationships. According to the results obtained from the numerical studies, it has been determined that the results obtained are not affected by the scale regardless of the scale of the hydraulic model. It has been determined that the difference between water celerity, impact velocity and maximum wave height values determined between all 3 methods varies between 2 $3 \%$. The results showed that the scale effect is insignificant for simple reservoirs and for short distances and empirical relationships may be sufficient for the calculations.
\end{abstract}

Keywords: Empirical Equations, Impact Velocity, Wave Height, Hydraulic Model, Impulse Wave, Numerical Model

*a Murat Karahan; muratkarahan@ktu.edu.tr, Tel: (0462) 37735 81, orcid.org/0000-0002-4500-0050

${ }^{\mathrm{b}}$ orcid.org/0000-0001-5556-547X c orcid.org/ 0000-0001-9571-4695 


\section{Giriş}

Kaya, çı̆̆g, buzul ve heyelan kütlelerinin belirli bir hız ve enerji ile doğal veya yapay su kütlelerine çarpması sonucu oluşan gravite dalgaları itki dalgaları olarak tanımlanmaktadır. Çoğunlukla, okyanuslarda, koylarda ve göllerde meydana gelmelerine karşın, dağllk bölgelerdeki baraj rezervuar alanlarında bulunan dik yamaçlardaki heyelan kütlelerinin hareketi ile oluşan itki dalgaları memba-mansapta bulunan yerleşim alanlarına, doğal habitata ve baraj gövdesine etki edebilmektedir. Bu dalgalar, özellikle üstten aşma sonucu barajlarda ciddi hasarlara hatta bazı durumlarda baraj yıkılmalarına neden olmaktadır. Üstten aşma ve yıkılma sonucunda yerleşim alanları büyük bir hız ve debiyle gelen suyun şiddetinden, taşkından ve taşkınla gelen molozdan olumsuz bir şekilde etkilenmekte hatta bazı durumlarda büyük ölçekli felaketler yaşanmaktadır.

Tarihte itki dalgası kaynaklı birçok felaket yaşanmıştır. Bu felaketler Unzen Dağı felaketi (1792), Krakato Yanardağı felaketi (1883), Lituya Bay heyelanı (1958), Vajont Baraj1 heyelanı (1963), Spirit Gölü heyelanı (1980), Hint Okyanusu Tsunamisi (2004), Nuugaatsiaq Fiyordu (2017) heyelanıdır. Bu vakalardan en trajik olanı Vajont Barajı göl alanında meydana gelmiştir. 9 Ekim 1963 yılında baraj gövdesi arkasındaki yamaçtan 300 milyon metreküp malzeme göl alanına doğru hareket etmiş ve 250 $\mathrm{m}$ yüksekliğinde dalga üretmiştir. Olay sonucu aktif depolama hacminin iki katı kadar malzeme göl alanına girerek rezervuar alanını doldurmuştur. Kütle hareketi sonucunda oluşan gravite dalgası baraj gövdesini yıkmamış ancak baraj gövdesinin aşarak dar bir vadi boyunca mansap kısmına doğru hareket etmiştir. Mansap kısmında su yüksekliği 70 metreye ulaşmış ve yerleşim alanlarının sular altında kalmasına neden olmuştur. Bu vaka sonucunda 2000 kişi hayatını kaybetmişsir (Özalp, 2018)
$\mathrm{Bu}$ nedenle bu tür dalgaların karşı kıyıdaki ilerleme miktarı (yatay-düşey yönde) ve baraj gövdesine ulaşan dalganın yüksekliğinin ve hızının bilinmesi büyük önem taşımaktadır. Oluşacak dalganın etkilerinin bilinmesi acil durum eylem planlarında göl ve rezervuar alanındaki yerleşim alanlarının boşaltılması için gerekli olan zamanın belirlenmesinde önemli rol oynaktadır. Örnek bir çalışmada, Yeni Zelanda'da Clyde Baraj1 rezervuar alanında bulunan heyelan kütlesinin olası hareketinin baraj gövdesi ve baraj göl alanındaki yerleşim yerleri için olumsuz etkiler doğuracağı yapılan hesaplamalar sonucunda tespit edilmiştir. Heyelan kütlesinin olası hareketi sonucu oluşacak gravite dalgasının etkisini en aza indirgemek için birtakım önlemler alınmıştır. Alınan önlemler kapsamında yerleşim alanları boşaltılmış, gövdenin yeri değiştirilmiş, çarpma kontrol altına alınmış, baraj yeniden tasarlanmış ve dalga payı yeniden hesaplanmıştır (MacFarlane ve Jenks, 1996).

Tüm bu gelişmelerden sonra, heyelan kaynaklı itki dalgaları ile ilgili çalışmalar son 20 yıl içerisinde önem kazanmıştır. Çalışmaların bir kısmı heyelan kütlesinin potansiyel enerjisinin dalga enerjisine dönüşmesi ile ilgili olup, heyelan kütlesinin konumunun ve şeklinin iletilen kinetik ve potansiyel enerji miktarı üzerindeki etkisi de araştırmalarda önemli yer tutmuştur (Wiegel, 1964; Sue vd., 2007). Buna ek olarak dağlık alanlarda, göl, gölet, baraj göl alanı ve kıyı kenarlarındaki kütle hareketi kaynaklı itki dalgalarının fiziksel özelliklerinin belirlenmesine yönelik 5 farklı yaklaşım önerilmiştir (Heller vd., 2009). Bunlar; (1) arazi verilerden elde edilen ampirik eşitliklerin kullanımı (Fritz 2002, Quecedo vd., 2004), (2) analitik değerlendirmeler (Di Risio, 2008), (3) laboratuar deneylerinden elde edilen ampirik eşitliklerin kullanımı (Hughes, 1993; Heller vd., 2008), (4) prototip özel modeller üzerinde yapılan deneyler ve (5) nümerik simülasyonlara dayalı modeller (Grilli vd., 2002; Montagna vd., 2011; Gabl vd., 2015) şeklinde siralanabilir (Tablo 1).

Tablo 1. Heyelan kaynaklı dalga özelliklerinin tahmininde kullanılan yöntemlerin karşılaştırılması (Heller vd., 2009).

\begin{tabular}{lccccc}
\hline Ölçütler & Yöntem (1) & Yöntem (2) & Yöntem (3) & Yöntem (4) & Yöntem (5) \\
\hline Sonuçların kalitesi & Kaba tahmin & Kaba tahmin & Tahmin & Kesin & Tahmin-kesin \\
Zaman & $\mathrm{Az}$ & $\mathrm{Az}$ & $\mathrm{Az}$ & Çok fazla & Fazla-Çok fazla \\
Maliyet & $\mathrm{Az}$ & $\mathrm{Az}$ & $\mathrm{Az}$ & Çok fazla & Fazla-Çok fazla \\
Kullanıc1 & Mühendis & Mühendis & Mühendis & Mühendis & Uzman \\
Parametre önemi & Orta & $\mathrm{Az}$ & Orta & Yüksek & Yüksek \\
\hline *(I) arazi verilerden elde edilen ampirik essitlikler (2) analitik değerlendirmeler (3) laboratuar deneylerinden elde edilen ampirik eşitlikler (4) \\
prototip özel modeller üzerinde yaplan deneyler (5) nümerik simülasyonlar
\end{tabular}


Son yıllarda heyelan kaynaklı itki dalgalarının özelliklerini tespit etmek için dalga makineleri tasarlanmış, granüler malzeme ve katı malzemeler kullanılarak 2 ve 3 boyutlu belirli ölçeklerde özel hidrolik model deneyler yapılmış, gerçekleşmiş olan vakaların prototip modelleri hazırlanarak deneyler uygulanmıştır. Yapılan çalışmalar sonucunda ampirik eşitlikler üretilmiş ve dalgaların oluşum ve yayılım özellikleri tespit edilmiştir (Fritz, 2002; Panizzo vd., 2005; Carvalho vd., 2006; Heller, 2007; Nieuwkoop, 2007, Di Risio vd., 2008). Ampirik eşitlikler pratikte hızlı ve kolay bir şekilde kullanılmakta ve oluşan gravite dalgasının özelliklerinin belirlenmesinde tahmin niteliğinde sonuçlar vermektedir. $\mathrm{Bu}$ tür eşitlikler dalganın ilk oluştuğu andaki özelliklerinin tahmininde kullanılabildiğinden (yükselik, hı vs), çalışmalarda büyük oranda rezervuar alanının geometrisi ihmal edilmektedir. Fakat itki dalgası büyük bir oranda su derinliğinin değişiminden ve rezervuar alanının şeklinden etkilenmektedir (Heller, 2009).

$\mathrm{Bu}$ nedenle son y1llarda analitik yöntemlerin yanı sira prototip model deneyler ve nümerik tabanlı çözümleme yöntemleri de yaygınlaşmaya başlamıştır. Tablo 1'de görüldüğü gibi prototip özel modeller üzerinde yapılan deneyler ve nümerik simülasyonlar elde edilen sonuçların kesin veya kesine yakın olduğu görülmektedir. Prototip özel deneyler kesin sonuçlar vermesine rağmen gerek ölçek etkisinden gerekse bu tür deneylerin pahalı olmasından dolayı pek tercih edilmemektedir. Ayrıca prototip özel model deneylerinde su derinliği en az $20 \mathrm{~cm}$ olacak şekilde ölçeklendirilmelidir (Heller vd., 2009). Çok büyük rezervuarlar için bu tür prototip özel modellerin kurulması çok zahmetli ve pahalı olduğu için, prototip modellerin yerine nümerik simülasyonlar tercih edilmektedir. Nümerik tabanlı çözümlemeler ile hem model deneyler hem de geçmişte meydana gelmiş vakalar üzerine de çalışmalar gerçekleştirilmiştir (Shi vd., 2015; Wang vd., 2016; Ersoy vd., 2019).

İtki dalgalarının oluşum mekanizması 3 ayrı fazda ele alınmaktadır. Bunlar; heyelan etkisiyle dalga oluşumu, dalganın rezervuarda yayılımı ve dalganın topografik bir yüzeye ve/veya baraj gövdesine çarpması şeklinde sıralanmaktadır. İtki dalgalarından kaynaklanacak etkilerin belirlenmesinde yukarıda siralanan 3 ayrı faz, bir bütün olarak değerlendirilmekte, ancak farklı modellerle analiz edilmektedir. Kütle hareketi kaynaklı oluşan itki dalgaların özelliklerini etkiyen en önemli parametrelerden biri kütlenin suya çarpma hızıdır. Çarpma hızını ise heyelan malzemesinin hacmine, kalınlığına, darbe hızına ve yamaç eğimine bağlıdır. $\mathrm{Bu}$ nedenle çalışmaların temelini heyelan malzemesinin hacminin, yanal ve düşey devamlılı̆̆ının belirlenmesi aşaması oluşturmaktadır (Şekil 1). İtki dalgasının fiziksel özellikleri ve yayılımı heyelan malzemesinin darbe etkisine, rezervuar şekline, derinliğine ve dalganın yayılım istikametine bağlıdır. İtki dalgalarının rezervuar kıyısında veya baraj gövdesindeki etkisi ise su derinliğine, dalga hızına, dalga yüksekliğine, karşı kıyı ve/veya baraj gövde eğimine bağlı olarak değişmektedir.

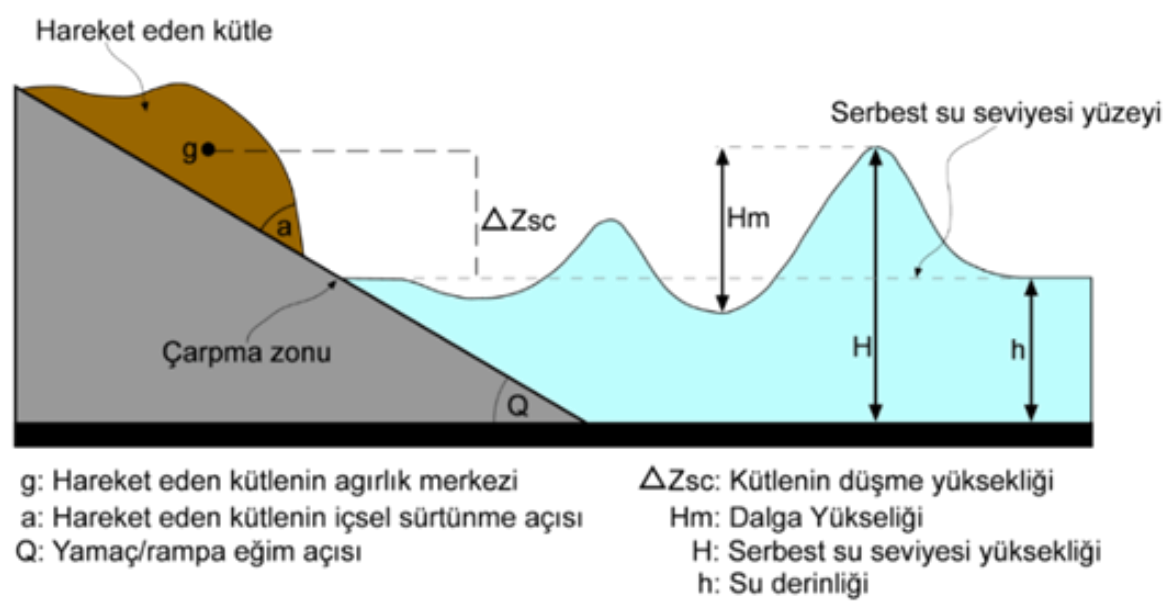

Şekil 1. İtki dalgasının oluşumu ve kütlenin suya çarpma hızının hesaplanmasında kullanılan parametreler

$\mathrm{Bu}$ çalışmada ise yukarıda belirtilen tüm açıklamalar dikkate alınarak itki dalgalarına ait hareket süresi, çarpma hızı ve yükseklik gibi fiziksel özellikler ampirik ilişkiler, hidrolik deneyler ve 3 boyutlu nümerik analizlerle belirlenmiş, itki dalgalarının oluşumunda ölçek etkisi nümerik tabanlı yaklaşımlarla değerlendirilmiştir. 


\section{Materyal ve Metot}

$\mathrm{Bu}$ çalışma kapsamında itki dalgalarının değerlendirilmesine yönelik; (1) ölçek etkisinin, (2) kayan kütlenin çarpma hızının, (3) çarpma süresinin ve (4) çarpma ile oluşacak dalga yüksekliğinin araştırılması amacıyla iki farklı aşama tanımlanmıştır. İlk aşamada laboratuvarda farklı koşullarda hidrolik bir model üzerinde fiziksel deneyler yapılmıştır. Deneylerde $2.00 \mathrm{~m} \mathrm{x}$ $0.42 \mathrm{~m} \times 0.47 \mathrm{~m}$ boyutlarında havuz, $1.35 \mathrm{~m} \mathrm{x}$ $0.39 \mathrm{~m} \times 0.22 \mathrm{~m}$ boyutlarında yükleme rampası, yüksek hızlı kamera ve akışkan olarak su kullanılmıştır. Sıvı ile deney yapılan modelin yüzeyi arasındaki sürtünmeyi en aza indirmek amacıyla ve kırılmaz olma özelliğe sahip olması nedeniyle havuz ve yükleme rampası $10 \mathrm{~mm}$ kalınlığında fiberglas malzeme kullanılarak inşa edilmiştir (Şekil 2). Fiberglasın esnememesi için kalınlık özellikle $10 \mathrm{~mm}$ olarak seçilmiş ve inşa edilen havuz çelik bir çerçeve üzerine oturtulmuştur. Fiberglas havuzun yerleştirildiği zeminin eğiminin olmamasına dikkat edilmiş ve böylelikle eğimin oluşturacağı olumsuz etkilere karşı önlem alınmıştır. Fiberglas havuzda ayrıca suyun tahliyesi için bir adet tahliye vanası da bulunmaktadır. Rampa 20-60 arasında eğim verilecek şekilde tasarlanmıştır. Bu sayede farklı acılarda akışkanın çarpma hızındaki değişimleri tespit etmek mümkün olacaktır. Yüksek hızla hareket eden akışkanın hareketini net bir şekilde görebilmek için görüntüyü $5 x$ ( $250 \mathrm{fps}), 10 x$ (500 fps) ve 20x (1000 fps) yavaşlatma özelliğine sahip olan yüksek hızlı bir kamera kullanılmıştır. Tüm fiziksel özelliklerinin bilinmesi nedeni ile deneylerde akışkan olarak su tercih edilmiştir.

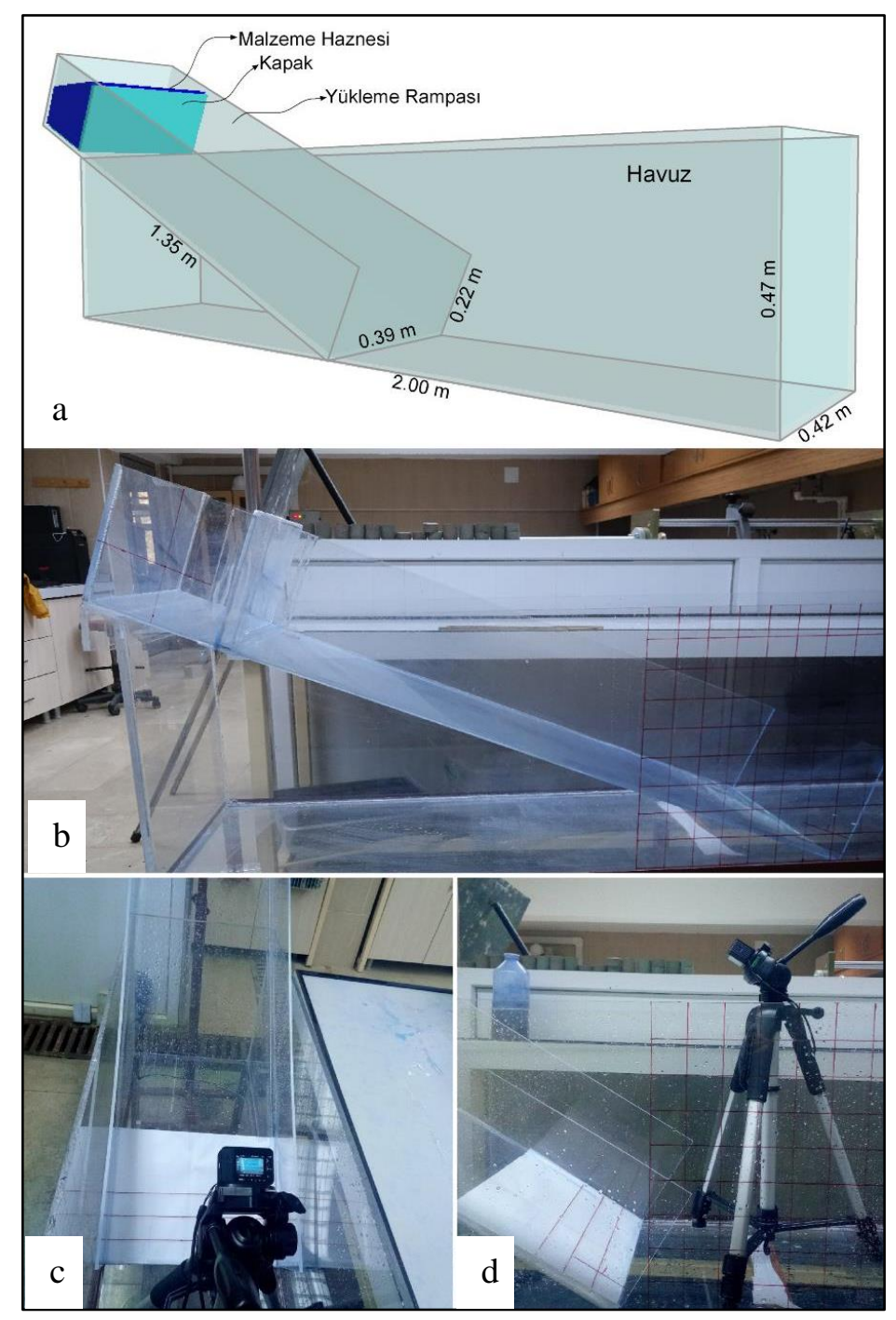

Şekil 2. (a) Deneylerde kullanılan fiber havuz, (b) yükleme rampası ve (c, d) yüksek hızlı kamera

İkinci aşamada ise kütlenin çarpma hızı ve çarpma ile oluşan dalganın yüksekliği (1) hidrolik model kullanarak, (2) ampirik eşitlikler ile ve (3) numerik analizlerle hesaplanmıştır, ölçek etkisi sadece nümerik olarak değerlendirilmiştir. Çalışmada, 3 boyutlu numerik analiz tabanlı 
FLOW-3D yazilımı (Flow Science Inc. 2017) kullanılarak laboratuvarda yapilan hidrolik deneyler 3 boyutlu olarak simüle edilmiştir.

Hesaplamalı akışkanlar dinamiği (CFD) yazılımı olan FLOW-3D, akışkan hareket denklemlerini çözmek için özel olarak geliştirilmiş sayısal analizler kullanmaktadır (Yin vd. 2015). Çalışmada "Drift-Flux Model" modülü tercih edilirken, dalga oluşumunu simüle etmek için "volume of fluid (VOF) model" modülü ile birlikte Reynolds Ortalamalı Navier-Stokes denklemlerini temel alan serbest yüzey modelleme tekniğini kullanılmıştır. Üç boyutlu katı model oluşturulurken Stereo Litografi (STL) dosyaları kullanılmış, modelin değerlendirilmesi sırasında oluşturulan simülasyonun hareket hızından dolayı, itki dalgası modelini oluşturmak için Drift-flux modeli ve Renormalize Grup (RNG) bazlı k-epsilon türbülans modeli uygulanmıştır.

Ölçek etkisinin araştırılmasında laboratuvarda yapılan deney gerçek ölçekli olarak bilgisayar programında modellenmiştir. Deneysel ve nümerik olarak kurulan modelde ölçülen serbest su seviyesi değerleri kıyaslanarak modelin doğruluğu test edilmiştir. Başlangıç aşamasındaki serbest su seviyeleri önemlidir çünkü; çarpma ile oluşan dalga solitary dalga olup bu tür dalgalarda dalga çukuru olmaz dalga yüksekliği serbest su seviyesi ile dalga tepesi arasındaki fark ölçülerek tespit edilmektedir. Sonrasinda modelin $0.1 \mathrm{x}, 1 \mathrm{x}$, $10 \mathrm{x}, 100 \mathrm{x}$ ve $1000 \mathrm{x}$ ölçekli modelleri nümerik model kullanılarak oluşturulmuştur. Kurulan modellerde faklı yoğunluklarda $\left(800-2000 \mathrm{~kg} / \mathrm{cm}^{3}\right)$ akışkanlar kullanılmış, her ölçek ve her yoğunluk için serbest su seviyesi değerleri tespit edilmiş ve farklı ölçeklerdeki fakat aynı yoğunluktaki serbest su seviyesi yüzeyleri kıyaslanarak ölçek etkisi araştırılmıştır. Programda farklı yoğunluklarda tanımlanan akışkanlarda hareket esnasında herhangi bir hava girişimi olmadığ 1 için başlangıç anındaki ve çarpma esnasındaki birim hacim ağırlıklar aynı olup değişmemektedir.

Çalışmada çarpma hızı hidrolik model deneylerle, ampirik eşitlikle ve nümerik olarak hesaplanmıştır. Kütlenin havuz tabanına çarpma hızı 3 farklı rampa açısı için hesaplanmıştır (20, 25 ve $30^{\circ}$ ). Deneyde yükleme havuzuna su doldurularak eğim aşağı boş havuz tabanına çarpması sağlanmış, çarpma etkisi ile oluşan dalga yüksekliği 30 derecelik rampa açısında ve $20 \mathrm{~cm}$ su derinliğinde hesaplanmıştır.

\section{3. Ölçek Etkisinin Araştırılması}

Heyelan kaynaklı itki dalgalarının değerlendirmesinde, arazi verilerinden yararlanılarak oluşturulan ampirik eşitlikler ve analitik değerlendirmeler kullanılarak yapılan analizler zaman, maliyet ve girdi parametrelerinin basitliği düşünüldüğünde değerlendirme kolaylığ1 açısından kullanışlı yöntemlerdir. Ancak her iki yöntemde de ölçek etkisi dikkate alınmamaktadır. Laboratuvar deneylerinden elde edilen ampirik eşitliklerin kullanımı itki dalgalarının fiziksel özelliklerinin tespitinde en çok tercih edilen yöntem olmasına karşın (Müller, 1995; Fritz, 2002; Panizzo, 2004; Zweifel, 2004; Heller, 2007) bu yöntemde rezervuar geometrisi, yamaç topografyası ve ölçek etkisi ihmal edilmektedir. Prototip modellerde uzun rezervuar geometrilerinin büyük ölçekte inşa edilmesi mümkün değildir. Ölçeğin küçültülmesi durumunda ise hassas sonuçlar elde edilememektedir. $\mathrm{Bu}$ nedenle çalışmada, yöntemlerin etkinliğini değerlendirmek amacıyla 3 boyutlu simülasyonlar kullanılarak ölçek etkisi araştırılmıştır.

Çalışmada kurulan hidrolik modelin ölçeğinin oluşan dalga özelliklerini etkileyip etkilenmediği farklı senaryolarda ve ölçekte model deney kurularak araştırılmıştır. $800,1200,1600$ ve 2000 $\mathrm{kg} / \mathrm{cm}^{3}$ yoğunluklarda sıv1 $1 \mathrm{x}, 10 \mathrm{x} 100 \mathrm{x}$ ve $1000 \mathrm{x}$ ölçeklerde aynı rampa eğiminde simüle edilmiş ve çarpma bölgesindeki serbest su seviyesindeki değişim tespit edilmiştir. Ölçek etkisinin olup belirlemek için aynı yoğunluktaki fakat farklı ölçeklerdeki serbest su seviyesi değerleri kıyaslanmıştır. Deneylerden elde edilen sonuçlar Şekil 3 ve Tablo2'de verilmiştir. Çalışmada farklı yoğunluklarda akışkan kullanılmasındaki amaç suyun yoğunluğu referans alınarak suyun yoğunluğundan az ve fazla akışkanlar içinde ölçek etkisinin olup olmadığını tespit etmektir.

Tablo 2. 2 Boyutlu çözümlemelere ait serbest su seviyesi değerleri

\begin{tabular}{ccccc}
\hline \multirow{2}{*}{$\begin{array}{c}\text { S1v1 } \\
\text { Yoğunluğu } \\
\left(\mathrm{kg} / \mathrm{m}^{3}\right)\end{array}$} & \multicolumn{4}{c}{ Serbest Su Seviyesi Değerleri $(\mathrm{m})$} \\
\cline { 2 - 5 } & $\mathrm{x} 1$ & $\mathrm{x} 10$ & $\mathrm{x} 100$ & $\mathrm{x} 1000$ \\
\hline 800 & 0.227 & 2.254 & 22.728 & 226.890 \\
1200 & 0.237 & 2.341 & 23.656 & 233.658 \\
1600 & 0.246 & 2.480 & 24.443 & 245.133 \\
2000 & 0.253 & 2.520 & 25.784 & 252.714 \\
\hline
\end{tabular}



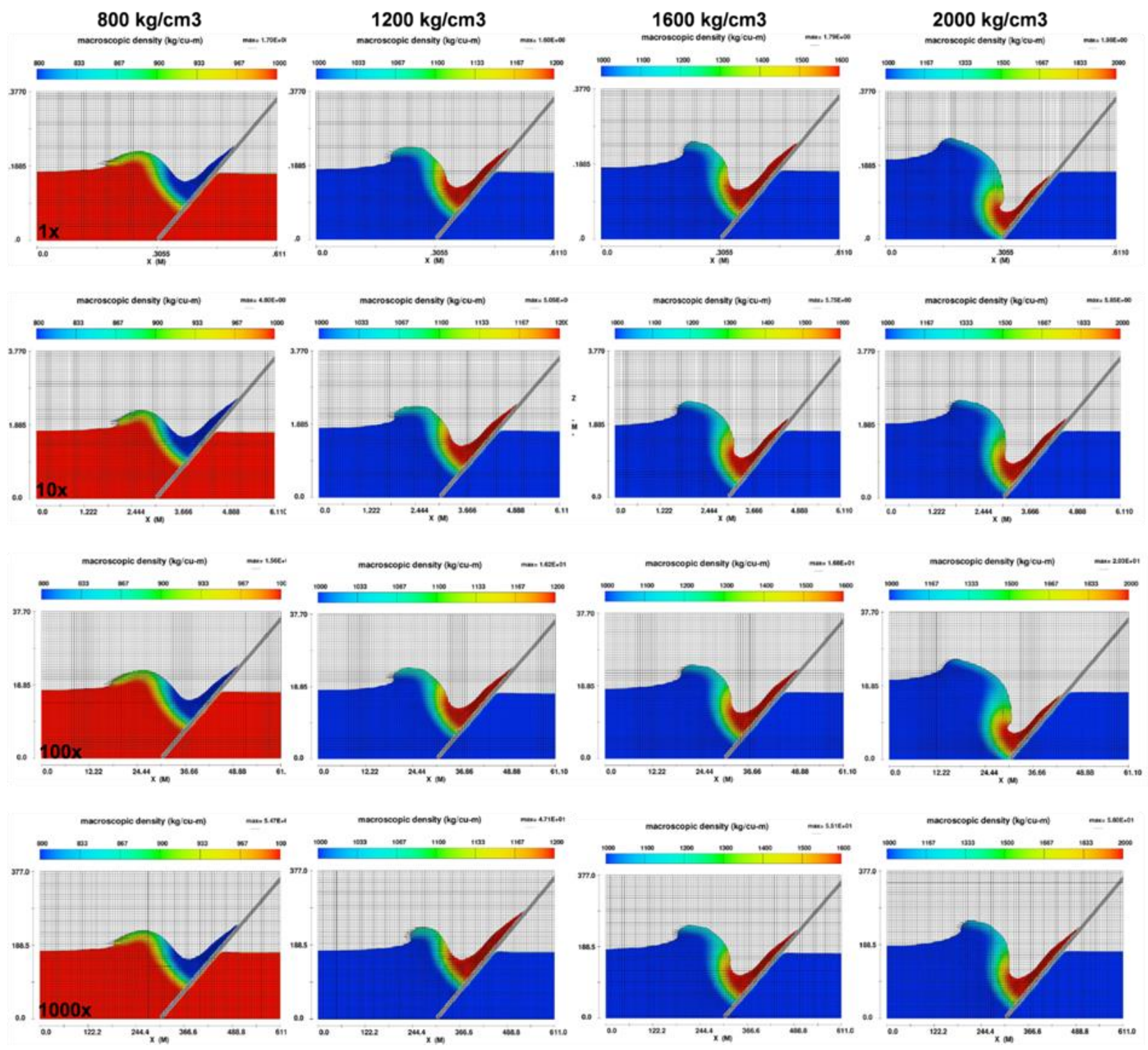

Şekil 3. Farklı yoğunluktaki ve ölçekteki simülasyonalar ait FLOW-3D programında yapılan 2 boyutlu çözümlemeler ( $\left.\mathrm{kg} / \mathrm{cu}-\mathrm{m}: \mathrm{kg} / \mathrm{m}^{3}\right)$

Elde edilen sonuçlar incelendiğinde aynı yoğunluktaki sıvıların serbest su seviyesi değerleri ölçek dahilinde artmıştır. Değerler gerçek boyutlu ölçeğe kıyasla normalize edildiği zaman her bir yoğunluk için ölçülen serbest su seviyesi değerinin yaklaşık eşit olduğu tespit edilmiştir. Bu durum Tablo 3'te belirgin bir şekilde görülmektedir.

Tablo 3. Gerçek boyutlu ölçeğe kıyasla normalize edilmiş değerler

\begin{tabular}{cccc}
\hline \multirow{2}{*}{$\begin{array}{c}\text { Sivı Yoğunluğu } \\
\left(\mathrm{kg} / \mathrm{m}^{3}\right)\end{array}$} & \multicolumn{3}{c}{$\begin{array}{c}\text { Normalize Edilmiş Serbest Su } \\
\text { Seviyesi Değerleri }\end{array}$} \\
\cline { 2 - 4 } & $\mathrm{x} 10$ & $\mathrm{x} 100$ & $\mathrm{x} 1000$ \\
\hline 800 & 0.23 & 0.23 & 0.23 \\
1200 & 0.23 & 0.24 & 0.23 \\
1600 & 0.25 & 0.24 & 0.25 \\
2000 & 0.25 & 0.26 & 0.25 \\
\hline
\end{tabular}

\section{4. Çarpma Hızının ve Süresinin Belirlenmesi}

Heyelan kütlesinin suya çarpma hızı, oluşan dalganın yüksekliğini, hızını, dalga boyunu ve karşı kıyıdaki ilerleme miktarını etkilemektedir. Aynı hacimde fakat farklı hızlardaki heyelan kütlesinin çarpma etkisi ile oluşturacakları dalga yükseklikleri birbirinden farklıdır. Çarpma hızı yüksek olan kütlenin oluşturacağ 1 dalga yüksekliği daha fazla olup oluşan dalganın ilerleme hızı da o denli fazla olacaktır. Bu nedenle gravite dalgalarında heyelan kütlesinin suya çarpma hızı değerinin doğru hesaplanması büyük önem taşımaktadır. Heyelan kütlesini suya çarpma hızını hesaplamak için ampirik eşitlikler üretilmiştir. Bu eşitlikler kullanılarak hareket eden kütlenin suya çarpma hızı pratik bir şekilde hesaplanabilmektedir. Ampirik ilişkilere ek olarak, çarpma hızı nümerik simülasyonlarla da 
çözülebilmektedir. Ancak 3 boyutlu nümerik tabanlı çözümlemelerde kullanıcı kaynaklı, modelin eksik kurulması ve sınır koşulların eksik tanımlanması sonucu hatalı sonuçlar elde edilebilmektedir. $\mathrm{Bu}$ tür hataları en aza indirmek için hidrolik deneylerin 3 boyutlu nümerik tabanlı modellerle çözümlenerek sonuçların kıyaslanması veya hibrit modellerin kurulması gerekmektedir.

Çalışma kapsamında, hareket eden kütlenin çarpma hızı ampirik eşitlikler, hidrolik deneyler ve 3 boyutlu nümerik simülasyonlar kullanılarak hesaplanmıştır. Hesaplamalar 20, 25 ve 30 derecelik açılara sahip rampalar için yapılmıştır. Ampirik eşitliklerde (Körner, 1976) tarafindan önerilen eşitlik kullanılmış, malzemenin içsel sürtünme açısı, yerçekimi ivmesi, rampa açısı ve düşme yüksekliği kullanılmıştır (Şekil 4). $v_{s}=\sqrt{2 g \Delta Z_{s c}(1-\operatorname{tana} x \cot Q)}$

Burada;

$\mathrm{v}_{\mathrm{s}}(\mathrm{m} / \mathrm{s})$ : kütlenin çarpma hızı

$\mathrm{g}\left(\mathrm{m} / \mathrm{s}^{2}\right)$ : yerçekimi ivmesi $\left(9.81 \mathrm{~ms}^{-2}\right)$

$\Delta \mathrm{Z}_{\mathrm{sc}}(\mathrm{m})$ : kütlenin düşme yüksekliği

$\mathrm{Q}\left({ }^{\circ}\right) \quad$ : yamaç/rampa eğimi

a $\left(^{\circ}\right) \quad$ : içsel sürtünme açıs1

Körner (1976) tarafından önerilen eşitlik kullanılarak 3 faklı açı değeri için suyun havuz tabanına çarpma hızı hesaplanmıştır. Hesaplamalarda suyun içsel sürtünme açısı sıfir olarak alınmış, su ile fiberglas rampa arasındaki sürtünme ihmal edilmiştir. Rampa açısının artması sonucu düşme yüksekliği de artmış, bu durum ise çarpma hızının artmasına neden olmuştur (Tablo 4).

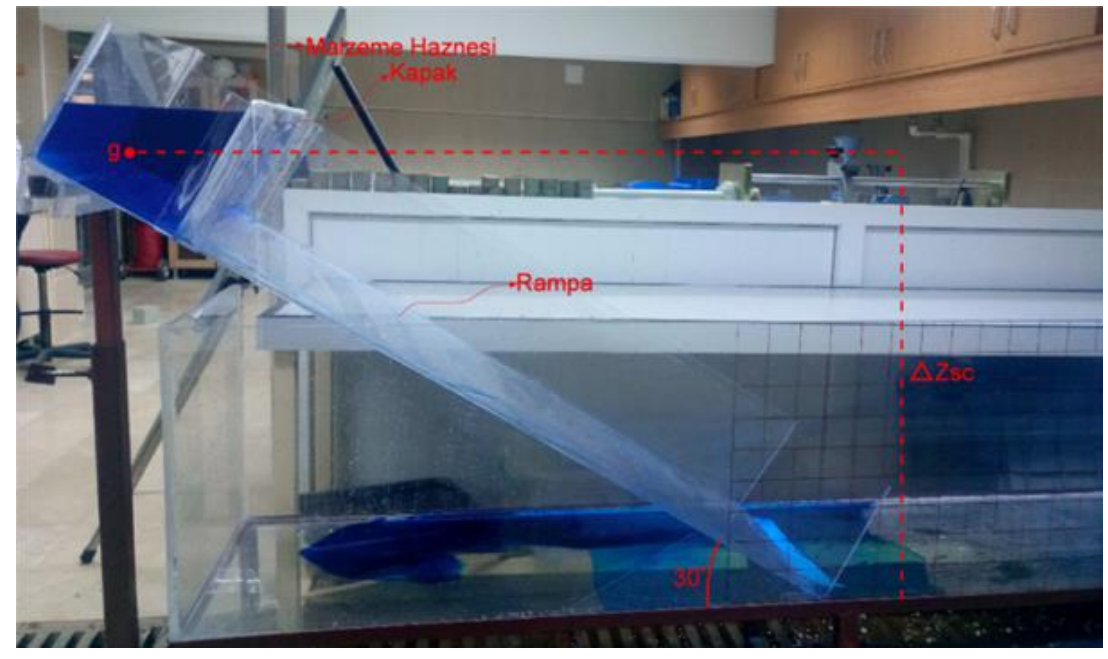

Şekil 4. Malzemenin çarpma hızının tespit edilmesi için kurulan 3 boyutlu laboratuvar modeli

Tablo 4. Farklı açı değerleri için çarpma hızı değerleri

\begin{tabular}{cccccc}
\hline $\begin{array}{c}\text { Model } \\
\text { deney }\end{array}$ & $\begin{array}{c}\text { Yamaç/rampa } \\
\text { eğimi }\left({ }^{\circ}\right)\end{array}$ & $\begin{array}{c}\text { Yerçekimi } \\
\text { ivmesi }\left(\mathrm{m} / \mathrm{s}^{2}\right)\end{array}$ & $\begin{array}{c}\text { Düşme } \\
\text { yüksekliği }(\mathrm{m})\end{array}$ & $\begin{array}{c}\text { İçsel sürtünme } \\
\text { açıs }\left(^{\circ}\right)\end{array}$ & $\begin{array}{c}\text { Çarpma hizı } \\
(\mathrm{m} / \mathrm{sn})\end{array}$ \\
\hline 1 & 20 & 9.81 & 0.53 & 0 & 3.22 \\
2 & 25 & 9.81 & 0.62 & 0 & 3.49 \\
3 & 30 & 9.81 & 0.72 & 0 & 3.76 \\
\hline
\end{tabular}

Çarpma hızının laboratuvarda hidrolik deneylerle ile tespit edilmesi için, hidrolik model yüksek hızlı kamera ve akışkan olarak metilen mavisi ile renklendirilmiş su kullanılmıştır. Deneylerde 20, 25 ve 30 derecelik açı değeri için hesaplamalar yapılmış, rampa istenilen açıya getirildikten sonra hazne renklendirilmiş su ile doldurulmuştur. Sonrasında haznenin kapağı açılarak yerçekimi etkisi ile suyun hareket etmesi sağlanmıştır. Hareket eden suyun çarpma hızı yükleme rampasının hemen bittiği noktaya yerleştirilen yüksek hızlı kamera ile çekilen videolar kullanılarak hesaplanmıştır. Yükleme rampansın son $15 \mathrm{~cm}$ 'lik kısmı üçe bölünerek $5 \mathrm{~cm}$ 'lik mesafeler tespit edilmiştir. Videolardan suyun 5 cm'lik mesafeyi kat etme süresi tespit edilmiştir. $\mathrm{Bu}$ sayede, bilinen mesafe ve süre kullanılarak suyun çarpma hızı belirlenmiştir (Tablo 5). Videolar 1000 fps (20x) hızında çekilerek 200 kat yavaşlatılmış ve bu sayede suyun $5 \mathrm{~cm}$ 'lik kısmı geçiş süresi tespit edilmiştir (Şekil 5). 
Tablo 5. Suyun çarpma hızının laboratuvar deneyleri ile tespit edilmesi

\begin{tabular}{ccccccc}
\hline $\begin{array}{c}\text { Rampa } \\
\text { eğimi }\end{array}$ & $\begin{array}{c}\text { Başlangıç } \\
\text { zamanı }\end{array}$ & $\begin{array}{c}\text { Bitiş } \\
\text { zamanı }\end{array}$ & $\begin{array}{c}\text { Varış süresi (200x } \\
\text { yavaşlatılmış) }(\mathrm{sn})\end{array}$ & $\begin{array}{c}\mathrm{t}(\mathrm{sn}) \\
\text { (gerçek süre) }\end{array}$ & $\mathrm{x}(\mathrm{m})$ & $\mathrm{v}(\mathrm{m} / \mathrm{sn})$ \\
\hline $20^{\circ}$ & $00: 02: 05.700$ & $00: 02: 08.800$ & 3.1 & 0.0155 & 0.05 & 3.23 \\
$25^{\circ}$ & $00: 02: 34.800$ & $00: 02: 37.700$ & 2.9 & 0.0145 & 0.05 & 3.45 \\
$30^{\circ}$ & $00: 00: 35.900$ & $00: 00: 38.600$ & 2.7 & 0.0135 & 0.05 & 3.70 \\
\hline
\end{tabular}

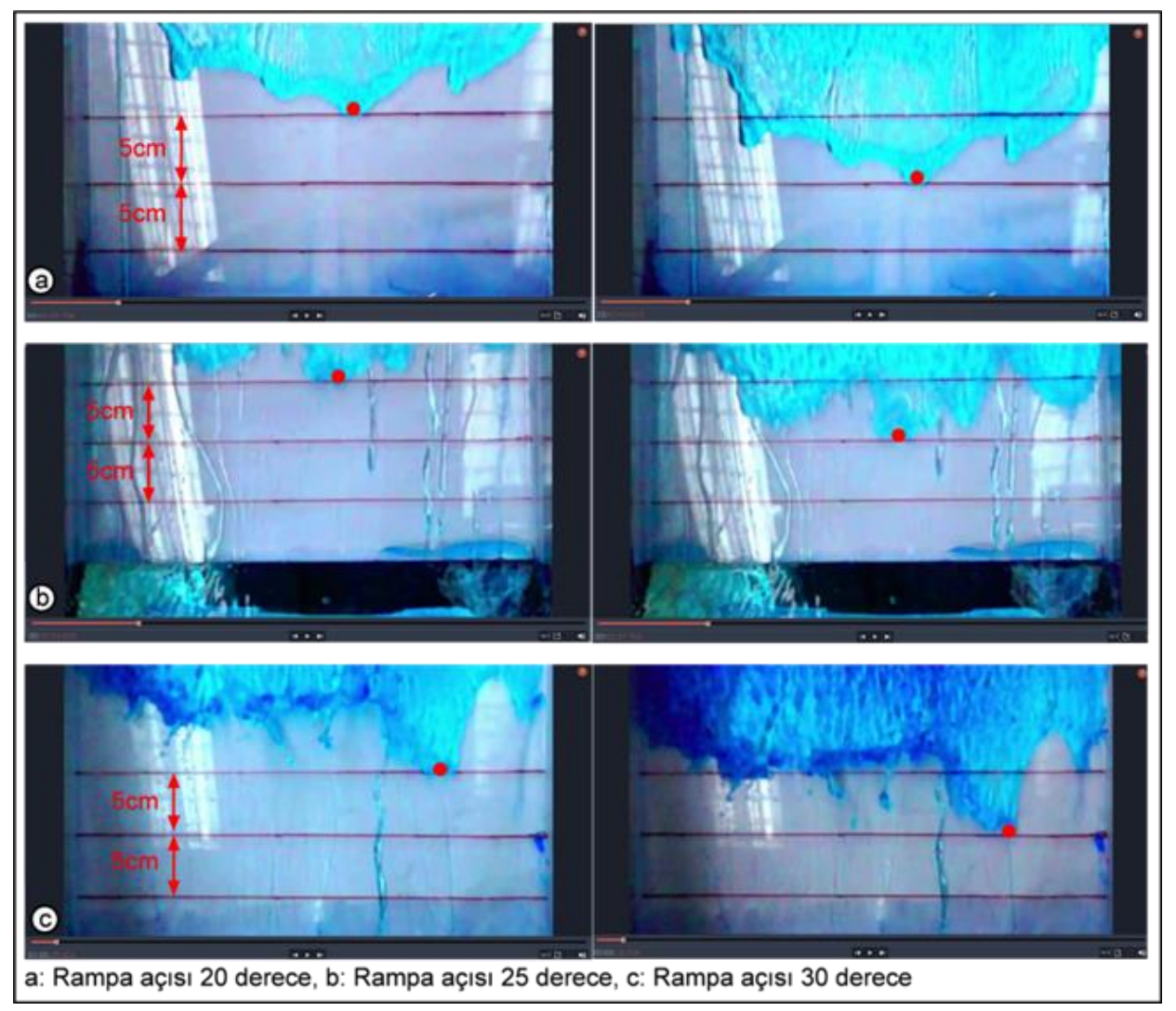

Şekil 5. (a) 20, (b) 25 ve (c) 30 derecelik rampalardan akan suyun havuz tabanına çarpma hızını tespit etmek için yüksek hızlı kamera ile çekilmiş görüntüler.

Çarpma hızının nümerik analiz ile tespit edilmesi için FLOW-3D ve SolidWorks (Premium, 2016) yazılımları kullanılmıştır. SolidWorks programı ile havuzun ve yükleme rampasının gerçek ölçekli 3 boyutlu katı modeli STL (STereoLithography) formatında tanımlanmıştır. Çizilen katı modeller kullanılarak FLOW-3D programında 3 farkl hidrolik deney modellenmiştir. Çözümlemede tek bir akışkan kullanılmış, akışkan olarak $20 \mathrm{C}^{\mathrm{o}}$ 'de ve $1000 \mathrm{~kg} / \mathrm{m}^{3}$ yoğunlukta su tanımlanmıştır. Çözümleme süresi 5 sn olarak ayarlanmış, düşey yöndeki yerçekimi ivmesi $9.81 \mathrm{~m} / \mathrm{sn}^{2}$ alınmış, suyun hareketinde hava girişimleri modelde tanımlanmıştır. Çözümlemelerde mesh boyutları $0.005 \mathrm{~m}$ olarak seçilmiş ve çözümlemede 7182000 hücre kullanılmıştır. 20,25 ve 30 derecelik rampa açıları için 3 boyutlu nümerik çözümlemeler kullanılarak elde edilen sonuçlar Tablo 6 ve Şekil 8 'de verilmiştir.
Çözümlemelerde renklendirmeler maksimum hız değerlerine göre yapılmış ve tam çarpma anındaki hız değerleri dikkate alınmıştır.

Tablo 6. Nümerik modellerle hesaplanan ve farkl1 eğimlerdeki rampalardan akan suyun havuz tabanına çarpma hızı değerleri

\begin{tabular}{cc} 
Rampa eğimi & Çarpma hızı $(\mathrm{m} / \mathrm{sn})$ \\
\hline $20^{\circ}$ & 3.219 \\
$25^{\circ}$ & 3.519 \\
$30^{\circ}$ & 3.755 \\
\hline
\end{tabular}



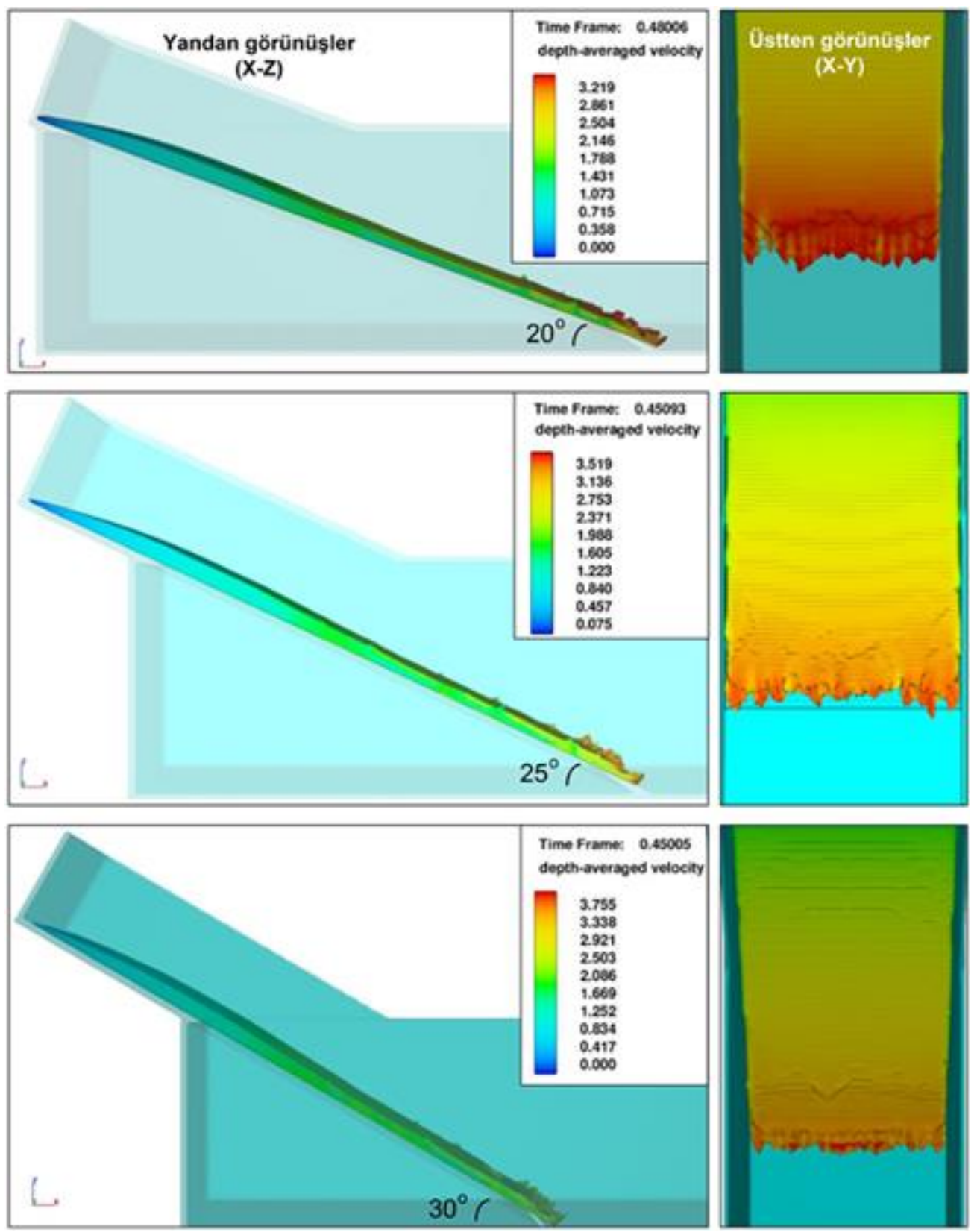

Şekil 6. 20, 25 ve 30 derecelik rampalardan akan suyun havuz tabanına çarpma hızını 3 boyutlu simülasyon ile hesaplanmas 1

Tablo 7. Farklı eğimdeki rampalardan akan suyun havuz tabanına çarpma hızı değerlerinin ampirik, hidrolik ve nümerik olarak hesaplanmış değerleri

\begin{tabular}{cccc}
\hline \multirow{2}{*}{$\begin{array}{c}\text { Rampa } \\
\text { eğimi }\end{array}$} & \multicolumn{3}{c}{ Suyun Çarpma Hızı (m/sn) } \\
\cline { 2 - 4 } & $\begin{array}{c}\text { Ampirik } \\
\text { eşitlik }\end{array}$ & $\begin{array}{c}\text { Hidrolik } \\
\text { model deneyi }\end{array}$ & $\begin{array}{c}\text { Nümerik } \\
\text { simülasyon }\end{array}$ \\
\hline $20^{\circ}$ & 3.22 & 3.23 & 3.219 \\
$25^{\circ}$ & 3.49 & 3.45 & 3.519 \\
$30^{\circ}$ & 3.76 & 3.70 & 3.755 \\
\hline
\end{tabular}

Çarpma hızının hesaplanmasına yönelik 3 farklı yöntemden elde edilen sonuçlar Tablo 7'de verilmiştir. Değerler karşılaştırıldığında her 3 yöntemden elde edilen sonuçların benzer olduğu görülmektedir.

Tablo 8. 3 Rampa açısı için varış sürelerinin hidrolik ve nümerik model olarak hesaplanması

\begin{tabular}{ccc}
\hline \multirow{2}{*}{ Rampa } & \multicolumn{2}{c}{ Varış süresi (sn) } \\
\cline { 2 - 3 } Eğimi & Hidrolik model & Nümerik model \\
\hline $20^{\circ}$ & 0.4850 & 0.48006 \\
$25^{\circ}$ & 0.4500 & 0.45093 \\
$30^{\circ}$ & 0.4450 & 0.4500 \\
\hline
\end{tabular}




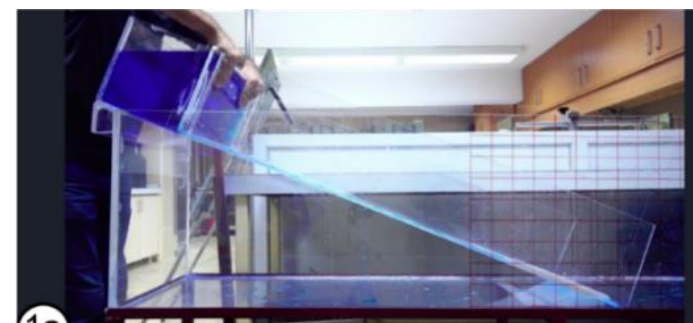

(1a)

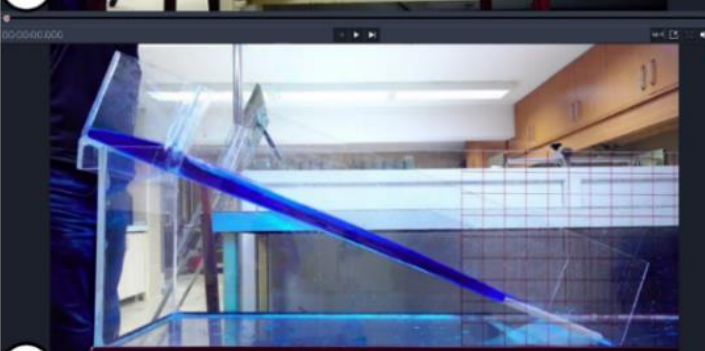

(2a)
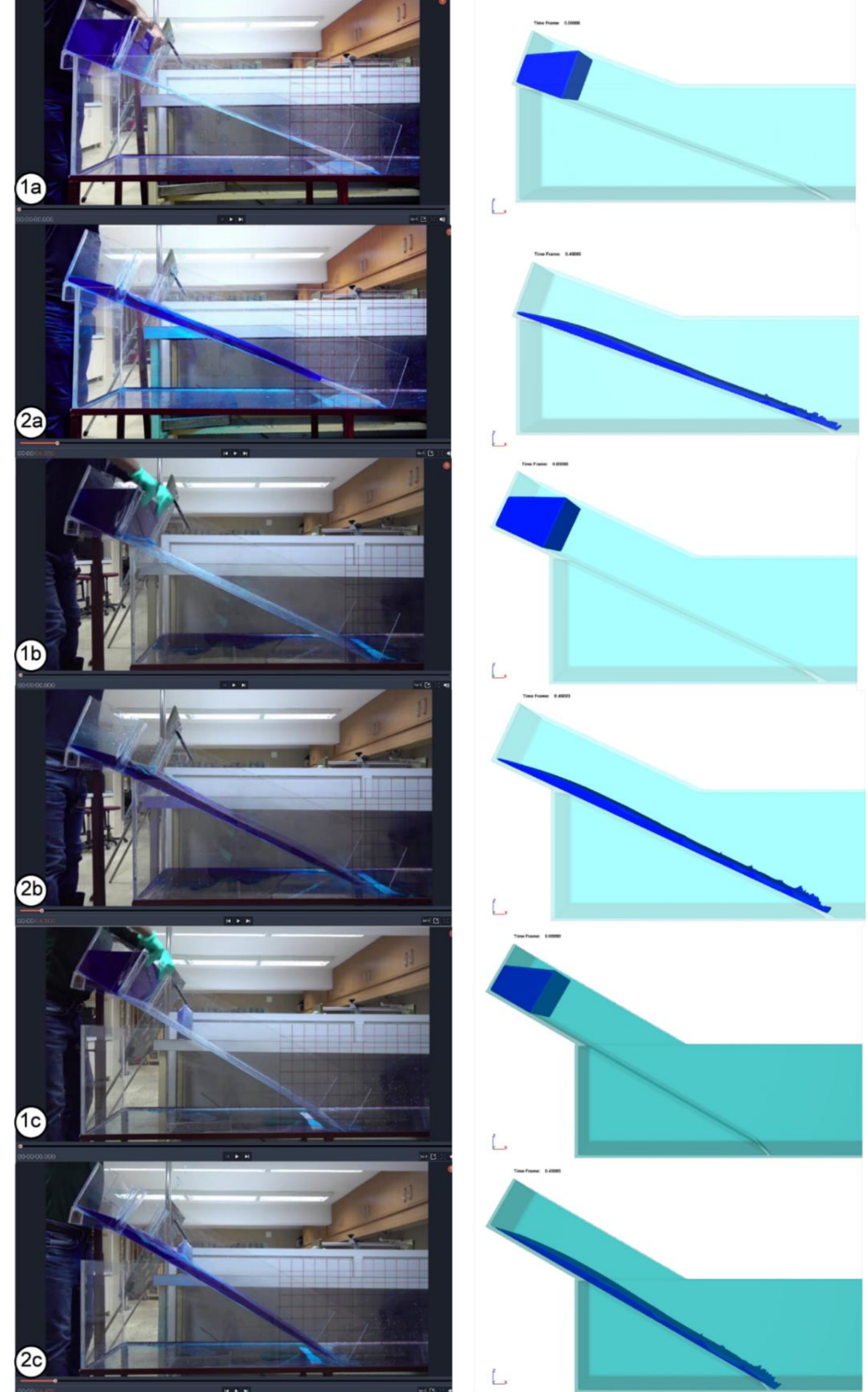

Şekil 7. (1a ve 2a) $20^{\circ}$, (1b ve $\left.2 \mathbf{b}\right) 25^{\circ}$ ve (1c ve 2 c) $30^{\circ}$ rampa açılarında suyun çarpma süresinin hidrolik deney ve 3 boyutlu nümerik analiz ile tespit edilmesi 


\section{Sonuçlar}

İtki dalgaları; çığ, buzul hareketleri, heyelanlar veya kaya düşmeleri sonucunda baraj rezervuar alanlarında darbe etkisiyle oluşan dalgalardır. 1963 yılında İtalya'daki Vajont Baraj1 rezervuarında gelişen bir heyelan sonucunda oluşan 250 metre yüksekliğindeki dalganın baraj1 aşarak binlerce insanın hayatını kaybetmesine neden olması, itki dalgalarının yıkıcı etkilerinin hangi boyutlara ulaşabildiğini gösteren en çarpıc1 örnektir. Heyelan kaynaklı itki dalgalarının analizine yönelik günümüze kadar birçok yöntem geliştirilmiş̧tir. Basit rezervuarlar için ampirik eşitlikler tercih edilse de bu yöntemler içinde en hassas sonuçlar simülasyona dayalı 3 boyutlu nümerik modellerden ve prototip modeller üzerinde yapılan laboratuvar deneylerinden elde edilmektedir. Bu çalışmada ise, en önemli itki dalga özelliği olan maksimum dalga yüksekliği ile itki dalgalarının fiziksel özellikleri üzerinde etkili olan malzeme hareket hızı ve çarpma hızı değerleri, 3 farklı yöntem kullanılarak irdelenmiştir. Buna ek olarak ölçek etkisinin dalga özellikleri üzerinde etkisi nümerik modellerle değerlendirilmiştir.

Çalışmada $2.00 \mathrm{~m} \times 0.42 \mathrm{~m} \times 0.47 \mathrm{~m}$ boyutlarında bir havuz ve $1.35 \mathrm{~m} \times 0.39 \mathrm{~m} \times 0.22 \mathrm{~m}$ boyutlarında bir yükleme rampası tasarlanmış, bu modelin STL geometrisi 3 boyutlu nümerik modelde tanımlanmıştır. Hidrolik model deneylerin gerçekleştirilmesi ve kaydedilmesi amacıyla ise yüksek hızlı bir kamera ve akışkan olarak su kullanılmıştır. Her 3 yöntem için aynı model kullanılmış ve elde edilen 3 ana sonuç aşağıda maddeler halinde sıralanmıştır;

(1) Çalışmada ölçek etkisini belirlemek için farklı senaryolarda ve ölçekte model deney kurulmuş, $800,1200,1600$ ve $2000 \mathrm{~kg} / \mathrm{cm}^{3}$ yoğunluklarda sıvı 1x, 10x 100x ve 1000x ölçeklerde aynı rampa eğimlerinde serbest akışa bırakılmıştır. Her yoğunluk ve her farklı eğim için elde edilen değerler normalize edildiğinde ölçek etkisinin söz konusu olmadığı tespit edilmiştir.

(2) Gerek hidrolik model üzerinde yapılan deneylerden, gerek 3 boyutlu nümerik çözümlemelerden gerekse ampirik eşitlikler kullanılarak yapılan hesaplamalardan elde edilen su akış hızı, çarpma hızı ve maksimum dalga yüksekliği değerlerinin birbirlerine çok yakın olduğu, farkların \%2-3 arasında kaldığ belirlenmiştir.
(3) Elde edilen tüm sonuçlar ve yapılan değerlendirmeler, basit geometriler ve kisa mesafeler için itki dalgalarının özelliklerinin belirlenmesinde uygulama kolaylığı açısından ampirik eşitliklerin kullanılabileceğini ve/veya aynı koşullar için ölçek etkisi söz konusu olmaması nedeniyle basit hidrolik modellerin kurulabileceğini göstermektedir.

\section{Kaynaklar}

Carvalho, R.F. ve Carmo, J.S.A., 2006. Numerical and Experimental Modelling of the Generation and Propagation of Waves Caused by Landslides into Reservoirs and Their Effects on Dams, Proceeding of the International Conference on Fluvial Hydraulics River Flow 6-8 September 2006, Lisbon, Portugal, Volume 1, p. 483-492.

Di Risio, M. ve Sammarco, P., 2008. Analytical Modeling of Landslide-Generated Waves. Journa of Waterway, Port, Coast and Ocean Engineering. 134, 53-60.

Ersoy, H., Karahan, M., Gelişli, K., Akgün, A., Anılan, T., Sünnetci, M.O. ve Yahşi, B.K., 2019. Modelling of the Landslide-Induced Impulse Waves in the Artvin Dam Reservoir by Empirical Approach and 3D Numerical Simulation. Engineering Geology, 249,112-128.

Flow Science, Inc. FLOW-3D Version 11.2 Documentation, Santa Fe, Newmexio, USA, 2016.

Fritz, H.M., 2002. Initial Phase of Landslide Generated Impulse Waves. PhD Thesis, Swiss Federal Institute of Technology. Zurich, Switzerland, $20 \mathrm{p}$.

Gabl, R., Seibl, J., Gems, B. ve Aufleger, M., 2015. 3D-Numerical Approach to Simulate an Avalanche Impact into a Reservoir. Natural Hazards Earth System Science, Discuss 3, 4121-4157.

Grilli, S.T., Vogelmann, S. ve Watts, P., 2002. Development of a 3D Numerical Wave Tank for Modeling Tsunami Generation by Underwater Landslides. Engineering Analysis with Boundary Elements, 26(4), 301-313.

Heller, V., 2007. Landslide Generated Impulse Waves Prediction of Near Field Characteristics. PhD thesis, Swiss Federal Institute of Technology in Zurich. Switzerland, 135-140p.

Heller, V., Hager, W.H. ve Minor, H.E., 2008. Scale Effects in Subaerial Landslide Generated Impulse Waves. Experiment of Fluids, 44, 691703. 
Heller, V., Hager, W.H. ve Minor, H.E., 2009. Landslide Generated Impulse Waves in Reservoirs Basics and Computation: Swiss Federal Institute of Technology in Zurich, Switzerland, 25p.

Heller, V. ve Kinnear, R.D., 2010. Discussion of (2009) Experimental Investigation of Impact Generated Tsunami; Related to a Potential Rock Slide, Western Norway by G. Sælevik, A. Jensen, G. Pedersen (Coastal Engineering 56:897-906). Coastal Engineering, 57(8), 773777.

Hughes, S., 1993. Physical Models and Laboratory Techniques in Coastal Engineering: World Scientific, Singapore, 63p.

URL-1, https://tr.qwertyu.wiki/wiki/List of Historical Tsunamis.

Körner, H.J., 1976. Reichweite und Geschwindigkeit von Bergstürzen und Fliessschneelawinen. Rock Mechanics and Rock Engineering, 8, 225-256.

Macfarlane, D.F., ve Jenks, D.G., 1996. Stabilisation and Performance of No. 5 Creek Slide, Clyde Power Project, New Zealand, In Proceedings of the 7th International Symposium on Landslides, Trondheim, Edited by Sennest, K. Balkema, A. A., Rotterdam, Volume 3, 1739-1746p.

Montagna, F., Bellotti, G. ve Di Risio, M., 2011. 3D Numerical Modeling of Landslide-Generated Tsunamis Around a Conical Island. Natural Hazards, 58(1), 591-608.

Müller, D.R., 1995. Auflaufen und Überschwappen von Impulswellen an Talsperren. Mitteilungen 137, Versuchsanstalt für Wasserbau, Hydrologie und Glaziologie. Swiss Federal Institute of Technology. Zurich, Switzerland, 40p.

Nieuwkoop, J.C. ve Van, C., 2007. Experimental and Numerical Modelling of Tsunami Waves Generated by Landslides. Msc Thesis, Delft University of Technology. Nederland, 40-45p.

Özalp, S., 2018. Tsunami: Yerküremizin Dev Dalgaları. Doğal Kaynaklar ve Ekonomi Bülteni, 26, 33-39.

Panizzo, A., 2004. Physical and Numerical Modelling of Subaerial Landslide Generated Waves. Ph.D.
Thesis, Universit'a Degli Studi di L'Aquila, L'Aquila. Italy, 120-125p.

Panizzo, A., De Girolamo, P. ve Petaccia, A., 2005. Forecasting Impulse Waves Generated by Subaerial Landslides. Journal of Geophysical Research Oceans, 110, 1978-2012.

Quecedo, M., Pastor, M. ve Herreros, M.I., 2004. Numerical Modelling of Impulse Wave Generated by Fast Landslides. International Journal for Numerical Methods in Engineering, 59, 1633-1656.

Shi, C.Q., An, Y., Q. ve Liu, Q., 2015. LandslideGenerated Impulse Waves in Deep V Channel: Runup and Near Field Characteristics. 7th International Conference on Fluid Mechanics, $126,232-236 \mathrm{p}$.

Solidwork Premium SP5, Concord, Massachusetts, USA, 2016.

Sue, P., 2007. Modelling of Tsunami Generated by Submarine Landslides. $\mathrm{PhD}$ thesis in Civil Engineering, University of Canterbury. New Zealand, 145-156p.

Wang, F., Zhang, Y., Huo, Z., Peng, X., Wang, S. ve Yamasaki, S., 2008. Mechanism for the Rapid Motion of the Qianjiangping Landslide During Reactivation by the First Impoundment of the Three Gorges Dam Reservoir, China. Landslides, 5, 321-329.

Wang, L., Chen, ZY., Wang, NX., Sun, P., Yu, S., Li, SY. ve Du, XH., 2016. Modeling Lateral Enlargement in Dam Breaches Using Slope Stability Analysis Based on Circular Slip Mode. Engineering Geology, 209, 70-81.

Wiegel, R.L., 1964. Oceanographical Engineering: Prentice-Hall, Englewood Cliffs, N.J.

Yin, Y., Huang, B., Chen, X., Liu, G. ve Wang, S., 2015. Numerical Analysis of Wave Generated by the Qianjiangping Landslide in Three Gorges Reservoir, China. Landslides, 7, 339-349.

Zweifel, A., 2004. Impulswellen Effekte der Rutschdichte und der Wassertiefe. Swiss Federal Institute of Technology. Zurich, Switzerland. 